\title{
Fundamental Tactical Principles of Soccer: a Comparison of Different Age Groups
}

\author{
by \\ Paulo Henrique Borges ${ }^{1}$, José Guilherme ${ }^{2}$, Leandro Rechenchosky1, \\ Luciane Cristina Arantes da Costa ${ }^{1}$, Wilson Rinadi ${ }^{1}$
}

The fundamental tactical principles of the game of soccer represent a set of action rules that guide behaviours related to the management of game space. The aim of this study was to compare the performance of fundamental offensive and defensive tactical principles among youth soccer players from 12 to 17 years old. The sample consisted of 3689 tactical actions performed by 48 soccer players in three age categories: under 13 (U-13), under 15 (U-15), and under 17 (U-17). Tactical performance was measured using the System of Tactical Assessment in Soccer (FUT-SAT). The Kruskal Wallis, Mann-Whitney U, Friedman, Wilcoxon, and Cohen's Kappa tests were used in the study analysis. The results showed that the principles of "offensive coverage" $(p=0.01)$ and "concentration" $(p=0.04)$ were performed more frequently by the U-17 players than the U-13 players. The tactical principles "width and length" $(p<0.05)$ and "defensive unit" $(p<0.05)$ were executed more frequently by younger soccer players. It can be concluded that the frequency with which fundamental tactical principles are performed varies between the gaming categories, which implies that there is valuation of defensive security and a progressive increase in "offensive coverage" caused by increased confidence and security in offensive actions.

Key words: soccer, fundamental tactical principles, youth players.

\section{Introduction}

For a long period, interpretations of soccer education were based on excessive appreciation of the physical dimensions and techniques of soccer and traditional concepts of training that arose primarily from the Cartesian paradigm (Casarin et al., 2011). However, the introduction of didactic and pedagogical proposals in recent years has contributed to overcoming these traditional approaches, making space for new methodologies guided by a systemic paradigm and allowing the tactical dimension to take on a guiding role in the entire process of teaching-learning-training (TLT) (Garganta and Gréhaigne, 1999; Greco and Benda, 1998).

Within this new epistemological movement of sports pedagogy, developing and evaluating tactical dimensions for different age groups has proven to be critical to the TLT programme, requiring new protocols and assessments. Various research studies have been proposed that aim to fill this demand. Published in 1997, the "Team Sports Performance Assessment Procedure" (Gréhaigne et al., 1997) was based on an evaluation of the behaviours exhibited in the offensive phase of the game. The following year, Oslin et al. (1998) validated the "Game Performance Assessment Instrument", which is notable as it evaluates some of the qualities of tactical-technical order in the first years of sports training. More recently, Costa et al. (2011b) validated the "System of Tactical

1 - Department of Physical Education, State University of Maringá, Brazil.

2 - Faculty of Sports, University of Porto, Portugal. 
Assessment in Soccer" (FUT-SAT) instrument. The FUT-SAT involves a field test and is notable for its assessment of the fundamental tactical principles of the offensive and defensive phases of the game, providing more precise information about the test result and game performance.

These assessment tools allow teachers and soccer coaches to understand how different factors influence tactical performance. Currently, research suggests that tactical behaviours exhibited by youth soccer players are related to motor impulsiveness (Andrade et al., 2016), being manifested in different ways depending on each player's specific knowledge (Giacomini et al., 2011), experience, position and game category (Padilha et al., 2013), match status (Lago, 2009), the quartile of birth (Andrade and Costa, 2015; Costa et al., 2010b) as well as on the training methodology (Aquino et al., 2015). Américo et al. (2016) reported that tactical behavior efficiency tended to increase over age categories and Borges et al. (2015) showed that the level of somatic maturity exerted a small influence on tactical indicators.

Despite a considerable increase in recent years in the number of studies related to tactical performance, only few have actually investigated how tactical principles operate among 12- to 17year-old players. The intense body changes resulting from the processes of growth and development during these ages justify an increase in research in this population (Malina et al., 2000). Furthermore, this information could prove valuable for soccer coaches and teachers, helping them to organize and plan the content essential to the TLT process and promoting better understanding of tactical performance in different age groups. Therefore, the aim of this study was to compare the performance of offensive and defensive fundamental tactical principles in the U13, U-15, and U-17 categories.

\section{Methods}

\section{Participants}

Eighty-six youth male soccer players between 12 and 17 years old who were part of an extension project of the State University of Maringá - Brazil were pre-selected to participate in the study. The following inclusion criteria were adopted: (1) participation in systematic training in the sport for at least one year; (2) absence of any muscular or skeletal injuries; (3) participation in regional and/or state competitions; (4) attendance at training sessions at least three times a week; and (5) Free and Clarified Consent Term (FCCT) signed by a parent or guardian. The final sample consisted of 48 players, with 12 players in the U13 category (12.70 \pm 0.56 years), 15 players in the U-15 category (14.52 \pm 0.49 years), and 21 players in the U-17 (16.21 \pm 0.59 years) category. The project was approved by the State University of Maringá (Opinion 653.698).

\section{Fundamental tactical principles}

The players' tactical performance was evaluated by the System of Tactical Assessment in Soccer (FUT-SAT), developed and validated by Costa et al. (2011b) to be used specifically for soccer during the sports training phase. The purpose of the test is to evaluate the management of game space, taking into consideration tactical actions in relation to the ball, teammates and opponents (Costa et al., 2011a, 2011b). The FUTSAT analyzes five offensive tactical principles (penetration, offensive coverage, width and length, depth mobility, and offensive unit) and five defensive tactical principles (delay, defensive coverage, balance, concentration, and defensive unit) and adopts the frequency of each principle as the final score (Frame 1).

\section{Procedures}

For test performance, the players were recorded with a digital Samsung HMX-F80 video camera as they executed the GR3-3GR field test (Costa et al., 2009). The videos were analysed using Soccer Analyser ${ }^{\circledR}$ software. This software was built specifically to assist in FUT-SAT analysis; it inserts spatial references into the video, allowing for a more rigorous evaluation of the positioning and movement of players on the field (Costa et al., 2011a). The assessments totalled 3689 tactical actions.

\section{Statistical Analysis}

All data were analysed using SPSS 20.0. The normality of the data was verified through the Shapiro-Wilk test. After identifying the need to use nonparametric statistics, the Kruskal-Wallis test was used to identify differences between the U-13, U-15 and U-17 groups, and subsequently the Mann-Whitney $U$ test was utilized to identify the source of the differences. To determine if there were any significant differences between the tactical principles, the Friedman test was 
performed followed by Wilcoxon pairwise comparisons. Regarding the Tactical Performance Index, $377(10.2 \%)$ of the actions were reevaluated by two researchers, trained and qualified to use the FUT-SAT. The reliability of the assessments of tactical behaviour was calculated using the Cohen's Kappa test, which indicated agreement above $81 \%$ in all cases. The level of significance was set at $p<0.05$.

\section{Results}

Tables 1 and 2 present comparisons of the frequency of the group performances of the offensive and defensive tactical principles:

As shown in Tables 1 and 2, the offensive tactical principle "width and length" $(\mathrm{Md}=12.00$; $\mathrm{Q} 1=8.25 ; \mathrm{Q} 3=15.75)$ and the defensive principle "defensive unit" $(\mathrm{Md}=13.00 ; \mathrm{Q} 1=11: 00 ; \mathrm{Q} 3=$
17.00) were most frequently performed by the study participants $(p<0.05)$. With regard to the overall aspects, the "offensive coverage" $(\mathrm{Md}=$ 7.50; $\mathrm{Q} 1=5.00 ; \mathrm{Q} 3=10.00)$ and "delay" $(\mathrm{Md}=8.00$; $\mathrm{Q} 1=5.00 ; \mathrm{Q} 3=10.00$ ) principles also stood out in terms of frequency of execution.

The comparison of the absolute frequencies of the tactical principles exhibited by the U-13, U-15 and U-17 categories is shown in Table 3. Offensively, the U-17 players executed the principle "offensive coverage" more often than the U-15 and U-13 groups ( $p=0.01$ ).

In terms of defence, the U-13 group performed the principle "concentration" $(p=0.04)$ less often than the U-17 group, while total defensive tactical actions proved to be higher as the age group increased $(p=0.01)$.

\begin{tabular}{|c|c|c|c|}
\hline \multicolumn{4}{|c|}{$\begin{array}{l}\text { Frame } \mathbf{1} \\
\text { Categories, sub-categories and variables assessed by the FUT-SAT }\end{array}$} \\
\hline Categories & Sub-categories & Variables & Definitions \\
\hline \multirow{10}{*}{$\begin{array}{l}\text { Tactical } \\
\text { Principles }\end{array}$} & \multirow{5}{*}{ Offensive } & Penetration & $\begin{array}{c}\text { Movement of the player with the ball towards } \\
\text { the goal line }\end{array}$ \\
\hline & & Offensive coverage & $\begin{array}{l}\text { Offensive support to the player who has the } \\
\text { ball }\end{array}$ \\
\hline & & Depth Mobility & $\begin{array}{l}\text { Movement of the players between the final } \\
\text { defender and goal line }\end{array}$ \\
\hline & & Width and Length & $\begin{array}{l}\text { Movement of the player to extend and use the } \\
\text { effective play-space }\end{array}$ \\
\hline & & Offensive unity & $\begin{array}{l}\text { Movement of the last line of defenders } \\
\text { towards the offensive midfield to support the } \\
\text { offensive actions of teammates }\end{array}$ \\
\hline & \multirow{5}{*}{ Defensive } & Delay & $\begin{array}{l}\text { Actions to slow down the opponent's attempt } \\
\text { to move forward with the ball }\end{array}$ \\
\hline & & Defensive coverage & Defensive support to the "delay" player \\
\hline & & Balance & $\begin{array}{l}\text { Positioning of off-ball defenders in reaction to } \\
\text { the movements of attackers in an attempt to } \\
\text { achieve numerical stability or superiority in } \\
\text { the opposition relationship }\end{array}$ \\
\hline & & Concentration & $\begin{array}{l}\text { Positioning of off-ball defenders to occupy } \\
\text { vital spaces and protect the scoring area }\end{array}$ \\
\hline & & Defensive unity & $\begin{array}{l}\text { Positioning of off-ball defenders to reduce the } \\
\text { effective play-space of the opponents }\end{array}$ \\
\hline
\end{tabular}


Table 1

Comparison of the frequency of offensive tactical principles exhibited by youth soccer

\begin{tabular}{lcc}
\multicolumn{3}{c}{ players } \\
\hline Tactical principles & $\mathrm{Md}$ & $\mathrm{Q} 1-\mathrm{Q} 3$ \\
\hline Penetration & $2.00^{\text {bde }}$ & $1.00-4.00$ \\
Offensive coverage & $7.50^{\text {acde }}$ & $5.00-10.00$ \\
Depth Mobility & $1.50^{\text {bde }}$ & $1.00-3.00$ \\
Width and Length & $12.00^{\text {abce }}$ & $8.25-15.75$ \\
Offensive unity & $6.00^{\text {abcd }}$ & $4.00-10.00$ \\
\hline
\end{tabular}

Values are presented as median $(M d)$ and interquartile ranges. ${ }^{a}$ Significant

difference for penetration; 'bignificant difference for offensive coverage;

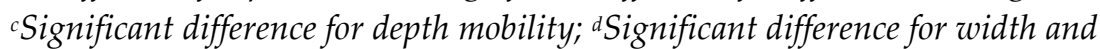
length; eSignificant difference for offensive unity. $p<0.05$.

Table 2

Comparison of the frequency of defensive tactical principles exhibited by youth soccer players

\begin{tabular}{lcc}
\hline Tactical principles & $\mathrm{Md}$ & $\mathrm{Q} 1-\mathrm{Q} 3$ \\
\hline Delay & $8.00^{\text {bde }}$ & $5.00-10.00$ \\
Defensive coverage & $1.00^{\text {acde }}$ & $0.00-2.00$ \\
Balance & $7.00^{\text {bde }}$ & $5.00-10.75$ \\
Concentration & $5.00^{\text {abce }}$ & $3.00-7.00$ \\
Defensive unity & $13.00^{\text {abcd }}$ & $11.00-17.00$ \\
\hline
\end{tabular}

Values are presented as median (Md) and interquartile ranges. ${ }^{a}$ Significant difference for delay; 'Significant difference for defensive coverage; 'Significant difference for balance; 'Significant difference for concentration; 'Significant difference for defensive unity. $p<0.05$.

\section{Table 3}

Comparison of the absolute frequency of tactical principles exhibited by $U-13, U-15$,

\begin{tabular}{lcccc}
\multicolumn{4}{c}{ and U-17 soccer players } & \\
\cline { 1 - 3 } & $\mathrm{U}-13$ & $\mathrm{U}-15$ & $\mathrm{U}-17$ & \\
\cline { 2 - 4 } & $\mathrm{Md}(\mathrm{Q} 1-\mathrm{Q} 3)$ & $\mathrm{Md}(\mathrm{Q} 1-\mathrm{Q} 3)$ & $\mathrm{Md}(\mathrm{Q} 1-\mathrm{Q} 3)$ & \\
\hline Penetration & $2.00(0.25-3.75)$ & $4.00(2.00-7.00)^{\mathrm{a}}$ & $2.00(0.00-3.00)^{\mathrm{b}}$ & 0.01 \\
Offensive coverage & $5.50(4.00-7.50)$ & $7.00(4.00-9.00)$ & $10.00(6.50-11.50)^{\mathrm{ab}}$ & 0.01 \\
Depth Mobility & $3.00(1.00-3.75)$ & $1.00(0.00-3.00)$ & $1.00(1.00-3.00)$ & 0.49 \\
Width and Length & $11.00(9.00-20.00)$ & $13.00(7.00-19.00)$ & $12.00(8.50-15.50)$ & 0.98 \\
Offensive unity & $4.50(3.00-6.50)$ & $8.00(4.00-10.00)$ & $7.00(5.00-11.50)$ & 0.05 \\
Total offensive & $28.00(23.25-35.75)$ & $33.00(24.00-37.00)$ & $33.00(28.50-40.50)$ & 0.12 \\
\hline & \multicolumn{3}{c}{ Defensive } & \\
\hline Delay & $5.50(4.25-9.50)$ & $8.00(5.00-12.00)$ & $8.00(7.00-10.00)$ & 0.22 \\
Defensive coverage & $1.50(0.00-2.00)$ & $1.00(0.00-2.00)$ & $2.00(1.00-2.00)$ & 0.56 \\
Balance & $6.50(4.25-8.50)$ & $7.00(5.00-10.00)$ & $9.00(7.00-11.00)$ & 0.09 \\
Concentration & $4.00(1.25-5.75)$ & $5.00(3.00-7.00)$ & $7.00(4.50-8.00)^{\mathrm{a}}$ & 0.04 \\
Defensive unity & $13.50(9.25-15.50)$ & $12.00(11.00-16.00)$ & $14.00(12.00-19.50)$ & 0.48 \\
Total defensive & $31.00(27.00-38.00)$ & $39.00(27.00-40.00)$ & $43.00(32.00-48.50)^{\mathrm{ab}}$ & 0.01 \\
\hline
\end{tabular}

Values are presented as median $(M d)$ and interquartile ranges. ${ }^{a}$ Significant difference for U-13; ${ }^{b}$ Significant difference for $U-15 . p<0.05$. 


\section{Discussion}

The aim of the study was to compare the performance of offensive and defensive tactical principles between the U-13, U-15 and U-17 categories. The primary results indicated that there were differences between the age groups: the principles "offensive coverage" and "concentration" were executed more frequently by the older groups. In addition, according to the results, the offensive tactical principle "width and length" and the defensive principle "defensive unity" were the most frequently implemented by the study participants ( $p>0.05)$.

The inferential statistics showed a significant increase in the performance of defensive tactical principles as the age group increased. The results indicate that the "total defensive" tactical actions were higher in the U-17 category compared to the U-13 and U-15 categories (Table 3). Although soccer is a very competitive sport, even at an early age and in the early stages of the TLT process, the link between increases in defensive behaviours and a higher age group can be explained by the increasing level of competition and greater exposure to the specific training mode. There is agreement that qualities of defensive efficiency are essential to the success of teams in terms of games won (Americo et al., 2013).

Specifically regarding the defensive fundamental principles, U-17 players executed "concentration" $(\mathrm{p}=0.04)$ more frequently compared to the U-13 group. The "concentration" principle is characterized by conditioning opponents for lower risk areas (Costa et al., 2009). Within the TLT process, it is natural for the players to exhibit different behaviours depending upon the characteristics of the various stages of sports training. The lower frequency of and greater difficulty in performing this principle during the defensive phase can be explained by the fact that the U-13 group undergoes a transition, a sporting orientation phase, characterized by experimenting with different positions and functions in a game in which learning the tactical-technical aspects must happen globally (Greco and Benda, 1998; Padilha et al., 2013).

There is also prevalence of "defensive unity" among 12- to 17-year-old soccer players at the defensive stage of the game (Table 2). In this sense, the importance given to each tactical principle is intimately related to each player's understanding of the game in combination with the game model built by the team (Kempe et al., 2014). The results indicate that both the unitary concept of defence behaviours and the movements executed outside the centre of the game, with the intention of ensuring an approach between the team's sectors, were performed similarly among the three categories. These behaviours indicate overall coordination within the entire team and ensure that players perform effectively when taking action to recover the ball.

"Offensive coverage" was higher in the U17 category in relation to the other categories $(\mathrm{p}=$ 0.01 ). The more effective participation of the U-17 group in providing support to the player with the ball represents better understanding of the game's logic. This can be explained by advances in cognitive development associated with biological processes as well as by experience gained in the process of sports training (Matias and Greco, 2010). Thus, it can be inferred that the U-13 and U-15 groups had difficulty performing consecutive actions to ensure possession of the ball; this principle is characterized by offering support for the ball's carrier and for creating numerical superiority in the central region of the game (Costa et al., 2009). Furthermore, research has shown different levels of initiative among players in performing tactical actions in the context of sports training. In recent decades, this has been a concern for the younger age groups. Teachers and technicians have been attempting to develop efficient methods to train tactically intelligent athletes, and research studies have been important to this effort (Hastie et al., 2013; Mesquita et al., 2012).

The "width and length" offensive principle (Table 1) had the highest frequency ( $\mathrm{Md}$ $=12.00)$, which is consistent with other studies (Americo et al., 2013; Sousa et al., 2015). These studies also found higher frequencies of performing this tactical principle during the offensive phase of a soccer game. Consequently, players tended to move between the line of the ball and the final defender, aiming to open the offensive play space in the transversal and longitudinal planes to allow the occupation of vital field space and gain more pass lines.

Although the literature in this field 
suggests that maintaining possession of the ball is a key element of excellence in sports performance (Añon et al., 2014; Lago and Martín, 2007), the present study observed a similar frequency of performing tactical principles that contributed to the manifestation of this behaviour, such as "depth mobility" ( $p=0.49)$, "width and length" ( $p$ $=0.98)$, and "offensive unity" ( $p=0.05)$. Thus, the content included in training should gradually increase in complexity with the aim of improving youth players' understanding of the game and tactical performance, leading to a higher quality of performance in U-17 players compared to U-15 players (Costa et al., 2010a). It is expected that the most advanced teams within the TLT programmes perform the principles such as "offensive unity" and " depth mobility" more frequently outside the play centre during the offensive phase.

In this sense, training content should encourage understanding of tactical actions from the beginning of the teaching and learning process in the school context. This seems to be fundamental to understanding soccer, a game of intelligence, for players in the younger categories. The importance of the teacher in achieving meaningful learning and providing an educational context that nurtures game situations, encouraging offensive and defensive tactical actions, can differentiate between athletes in the near future, greatly improving tactical soccer principles.

The teams investigated exhibited an increase in defensive tactical behaviours as the age group increased. However, the study did not identify a progressive increase in "total offensive" actions $(p=0.12)$. As practical implications for sport practice, it is recommended that teams and federations involved in training of youth players should also promote the offensive aspects of the game to encourage effective learning of the fundamental tactical principles (Tenga et al., 2010) as well as planning training content to increase in complexity throughout the game categories.

In terms of study limitations, there is a need for future research that uses a longitudinal research design, allowing monitoring of changes to and evolution of tactical behaviours in the entire sports training process. However, these results contribute to the better understanding of the performance of tactical principles by players in different age groups, enabling better targeting of training content during the early stages of the TLT process. The authors suggest that further research should be conducted in soccer schools in other regions of Brazil so that training methods can be compared and tactical principles shared in workshops and specialized courses organized at the national level.

\section{Acknowledgements}

The authors would like to express thanks to the NUPEF and the Coordination of the Improvement of Higher Education Personnel (CAPES) for the granted master's scholarship, which allowed realization of this research.

\section{References}

Americo HB, Cardoso FSL, Machado GF, Andrade MOC, Resende ER, Costa IT. Analysis of the tactical behavior of youth academy soccer players. J. Phys Educ, 2016; 27: 1-9

Americo HB, Machado GF, Costa IT. Comparison of tactical performance of players between U-11 and U-17 categories. Rev Min Educ Fís, 2013; 9: 715-721

Andrade MOC, Costa IT. How tactical behavior efficiency and birthdate affect performance of soccer players? Rev Bras Educ Fís Esporte, 2015; 29: 465-473

Andrade MOC, Machado GF, Teoldo IT. Relationship between impulsiveness and tactical performance of U15 youth soccer players. Hum Mov, 2016; 17: 126-130.

Añon IC, Lizana CJR, Calazans E, Machado JC, Costa IT, Scaglia AJ. Performance of Barcelona's team and their opponents in the finals matches of the Champions League and the FIFA Club World Cup 2010. Rev Andal Med Deporte, 2014; 7: 13-20 
Aquino RLQT, Marques RFR, Gonçalves LGC, Vieira LHP, Bedo BLS, Moraes C, Menezes RP, Santiago PRP, Puggina EF. Proposal of teaching systematization of soccer based on games: development of tactical knowledge in 10 to 11 years old players. Motricidade, 2015;11: 115-128

Borges $\mathrm{PH}$, Avelar A, Rinaldi W. Tactical knowledge process, physical performance and level of somatic maturation in young soccer players. Rev Bras Ci e Mov, 2015; 23: 88-96

Casarin RV, Reverdito RS, Greboggy DL, Afonso CA, Scaglia AJ. Model and play soccer in the process of education: global and specific principles. Movimento, 2011; 17: 133-152

Costa IT, Garganta J, Greco PJ, Mesquita. Tactical evaluation of performance in football: design and development of grid observation test GR3-3GR. Rev Min Educ Fís, 2009; 17: 36-64

Costa IT, Garganta J, Greco PJ, Mesquita I, Afonso J. Assessment of tactical principles in youth soccer players of different age groups. Rev Port Cien Desp, 2010; 10: 147-157a

Costa IT, Garganta J, Greco PJ, Mesquita I, Seabra A. Influence of relative age effects and quality of tactical behavior in the performance of youth soccer players. Int J Perform Anal Sport, 2010; 10: 82-97b

Costa IT, Garganta J, Greco PJ, Mesquita I. Proposal for tactical assessment of soccer player's behaviour regarding core principles of the game. Motriz, 2011; 17: 511-524a

Costa IT, Garganta J, Greco PJ, Mesquita I, Maia J. System of tactical assessment in soccer (FUT-SAT): Development and preliminary validation. Motricidade, 2011; 7: 69-84b

Garganta J, Gréhaigne JF. Systemic approach of soccer game: a case of fashion or need? Movimento, 1999; 10: $40-50$

Giacomini DS, Soares VO, Santos HF, Matias CJ, Greco PJ. Declarative and procedural tactical knowledge in soccer players of different ages. Motricidade, 2011; 7: 43-53

Greco PJ, Benda, RN. Universal sports initiation. Belo Horizonte: Editora da UFMG, 1998

Gréhaigne JF, Godbout P, Bouthier D. Performance assessment in Team Sports. J Teach Phys Educ, 1997; 16: 500-516

Hastie P, Calderón A, Rolim R, Guarino AJ. The Development of Skill and Knowledge During a Sport Education Season of Track and Field Athletics. Res Q Exerc Sport, 2013; 84: 336-344

Kempe M, Vogelbein M, Memmert D, Nopp S. Possession vs. Direct play: evaluating tactical behavior in elite soccer. Int J Sports Sci, 2014; 4: 35-41

Lago C. The influence of match location, quality of opposition, and match status on possession strategies in professional association football. J Sports Sci, 2009; 27: 1463-1469

Lago C, Martín R. Determinants of possession of the ball in soccer. J Sports Sci, 2007; 25: 969-974

Malina RM, Peña-Reyes ME, Eisenmann JC, Horta L, Rodrigues J, Miller R. Height, mass and skeletal maturity of elite Portuguese soccer players aged 11-16 years. J Sports Sci, 2000; 18: 685-693

Matias CJ, Greco JP. Cognition and action in team ball sports. Cognição e ação, 2010; 15: 252-271

Mesquita I, Farias C, Hastie P. The impact of a hybrid Sport Education-Invasion Games Competence Model soccer unit on students' decision making, skill execution and overall game performance. Eur Phys Educ Rev, 2012; 18: 205-219

Oslin JL, Mitchell SA, Griffin LL. The Game Performance Assessment Instrument (GPAI): development and preliminary validation. J Teach Phys Educ, 1998; 17: 231-243

Padilha MB, Moraes JC, Costa IT. Can positional statute influence tactical performance of U-13 youth soccer players? Rev Bras Ci e Mov, 2013; 21: 73-79 
Sousa RB, Soares VDOV, Praça GM, Matias CJADS, Costa IT, Greco PJ. Tactical behavior assessment in soccer: fundamental tactical principles between U-14 and U-15 players. Rev Bras Ci e Mov, 2015; 23: 5965

Tenga A, Ronglan LT, Bahr R. Measuring the effectiveness of offensive match-play in professional soccer. Eur J Sports Sci, 2010; 10: 269-277

\section{Corresponding author:}

Paulo Henrique Borges.

Department of Physical Education, State University of Maringá, Brazil

Street Domingos Mião, 309.

Postal code: 87023-025. City: Maringá-PR,

Brazil. 